\title{
Vertical Transmission of COVID 19 During Pregnancy
}

\author{
Devashree Nikose ${ }^{1}$ and Sunil Nikose ${ }^{2}$ \\ ${ }^{1}$ Post intern medical doctor, NKP Salve Institute Of Medical Sciences, Nagpur, India \\ ${ }^{2}$ Professor \& Director of Centre of Excellence of medical Simulation, Datta Meghe Institute Of Medical Sciences, India
}

Submission: July 6, 2020; Published: July 14, 2020

*Corresponding author: Sunil S Nikose, Professor of Orthopedic surgery, Director Centre of Excellence for medical simulation studies, Datta Meghe Institute of Medical Sciences, Sawangi, Meghe Wardha, India

\section{Abstract}

Viral pneumonia is considered to be among the most serious non-obstetric infectious disease correlated with maternal and neonatal morbidity and mortality during pregnancy. Coronavirus Disease (COVID-19), is a type of viral pneumonia caused by the SARS-CoV-2 virus, which highly infectious and has attained a pandemic state currently spreading rapidly across the world. Based on the literature available and as per our knowledge concern, it has been suggested that there is no effect of COVID on maternal and perinatal outcome of the pregnant women.

Keywords: COVID -19; Pandemic; Pregnant women; Viral pneumonia: Vertical transmission

\section{Commentary}

Coronavirus disease 2019 (COVID-19) is highly infectious disease associated to severe acute respiratory syndrome coronavirus 2 (SARS-CoV-2). Information regarding COVID-19 is advancing rapidly, and various organizations are continually updating and improving on interim guidelines. The current discussion will address the matters associated with COVID-19 during pregnancy and particularly the vertical transmission from mother to neonate. The data regarding maternal outcomes with COVID-19 infections during pregnancy are limited. However, data from other viral diseases such as SARS, MERS and influenza are more likely for pregnant women to develop viral pneumonitis [1]. Additionally, viral pneumonia is considered to be among the most serious non-obstetric infectious disease correlated with maternal and neonatal morbidity and mortality during pregnancy1. A typical coronavirus disease (COVID-19), caused by the SARS-CoV-2 virus, is highly infectious and is currently spreading rapidly across the world. It caused thousands of morbidities and deaths worldwide after SARS-COV-2 emerged in Wuhan, Hubei Province, China in December 2019 [2]. Many investigations have concentrated on general population infected patients; however, information of the COVID-19 female pregnancy outcomes are limited. Chen et al. [3] reported the maternal and neonatal outcome of COVID-19 pneumonia in pregnant women and the potential for vertical transmission. Their research focused on pregnant women who only delivered babies by $\mathrm{C}$-section, and no case for normal vaginal delivery was identified. Moreover, Healthcare staff has also not been included, since healthcare workers are at greater risk of infection and psychological consequences. The ICMR (Indian Council of Medical Research) recently in their report stated that antenatal and intrapartum vertical transmission from mother to baby is possible. However, the proportion of affected pregnancies and the significance for neonates is still to be established. There are currently no recorded cases of positive COVID 19 vaginal secretions test, and no recorded cases of positive COVID 19 breast milk test [4]. Women experience immunological and physiological changes during pregnancy that could make them more susceptible to viral respiratory infections, such as influenza, and severe acute respiratory syndrome (SARS) and Middle East respiratory syndrome (MERS) adverse outcomes of pregnancy have been observed [5]. There are no current definitive data in pregnant women regarding the clinical characteristics, morbidity, and mortality of coronavirus disease 19 (COVID-19). The question of vertical transmission has been addressed and no evidence of vertical transmission has been presented by the available literature (although with small groups of mothers infected with COVID-19). Some common viral infections, like as HIV, predispose to intrapartum neonatal transmission [3]. Very few evidences is available till date for the vertical transmission of COVID 19 during pregnancy. It has been revealed in one of the case series that three neonates were born vaginally, among them one singleton, 


\section{Global Journal of Reproductive Medicine}

one set of twins) and found negative for COVID-19 when throat swabs was taken for PCR at day one of birth in all three cases [6]. When vaginal swab tested during pregnancy of COVID-19 positive patient and had shown negative vaginal swab testing during delivery. Also, previous studies [3,6] evidences indicated no increased incidence of perinatal vertical infection transmission. Pathology analyses of three placentas of confirmed COVID-19 positive patients after caesarean section delivery showed no symptoms of villitis and chorio-amnionitis, and all three placental test sample were negative for COVID-19 RNA [7]. Based on these findings, no evidence for COVID-19 in second or third trimester vertical intrauterine transmission has been reported. Clinical investigation on the effects of COVID-19 during pregnancy is still in its early stages. Based on the literature available and as per our knowledge concern, it has been suggested that there is no effect of COVID on maternal and perinatal outcome of the pregnant women. Although the majority of mothers may discharge without any major complications and there were no evidence of vertical transmission of the COVID-19. However long-term monitoring of such babies is required to have any delayed effects. Therefore, governments and health officials should implement many policies to ensure the welfare of pregnant women.

\section{References}

1. Schwartz DA, Graham AL (2020) Potential Maternal and Infant Outcomes from (Wuhan) Coronavirus 2019-nCoV Infecting Pregnant Women: Lessons from SARS, MERS, and Other Human Coronavirus Infections. Viruses 12: 1-16.

2. Wang D, Hu B, Hu C, Zhu F, Liu X, et al. (2020) Clinical characteristics of 138 hospitalized patients with 2019 novel coronavirus-infected pneumonia in Wuhan, China. JAMA 323: 1061-1069.

3. Chen H, Guo J, Wang C, Luo F, Yu X, et al. (2020) Clinical characteristics and intrauterine vertical transmission potential of COVID-19 infection in nine pregnant women: a retrospective review of medical records. Lancet 395: 809-815.

4. (2020) Coronavirus pune newborn covid 19 positive woman tests negative. pp. 48826.

5. Buekens P, Alger J, Bréart G, Cafferata ML, Harville E (2020) A call for action for COVID-19 surveillance and research during pregnancy. Lancet Glob Health 8(7): e877-e878.

6. Liu Y, Chen H, Tang K, Guo Y (2020) Clinical manifestations and outcome of SARS-CoV-2 infection during pregnancy. J Infect S0163 4453(20): 30109-30112.

7. Chen S, Huang B, Luo DJ, Li X, Yang F, et al. (2020) Pregnant women with new coronavirus infection: a clinical characteristics and placental pathological analysis of three cases. 49(5): 418-423.

Your next submission with Juniper Publishers
will reach you the below assets
- Quality Editorial service
- Swift Peer Review
- Reprints availability
- E-prints Service
- Manuscript Podcast for convenient understanding
- Global attainment for your research
- Manuscript accessibility in different formats
( Pdf, E-pub, Full Text, Audio)
- Unceasing customer service
Track the below URL for one-step submission
https://juniperpublishers.com/online-submission.php

